\title{
Determination and Application of Maximum Efficiency Curve of Crawler Electric Tractor Motors
}

\author{
Jing Liu $\mathbb{D},{ }^{1,2}$ Changgao Xia $\left(\mathbb{D},{ }^{1}\right.$ Donglin Jiang, ${ }^{2}$ Gaogao Shang, ${ }^{1}$ Jiangyi Han, ${ }^{1}$ and Yan Sun ${ }^{1}$ \\ ${ }^{1}$ School of Automotive and Traffic Engineering, Jiangsu University, Zhenjiang, Jiangsu, China \\ ${ }^{2}$ Nanjing Vocational Institute of Transport Technology, Nanjing, Jiangsu, China \\ Correspondence should be addressed to Changgao Xia; xiacg@ujs.edu.cn
}

Received 26 September 2021; Accepted 4 December 2021; Published 23 December 2021

Academic Editor: Min Ye

Copyright (C) 2021 Jing Liu et al. This is an open access article distributed under the Creative Commons Attribution License, which permits unrestricted use, distribution, and reproduction in any medium, provided the original work is properly cited.

With the excessive use of fossil fuels such as oil, the energy crisis and environmental pollution have become important problems related to people's livelihoods. In agriculture, as a new type of green agricultural machinery, the electric tractor has the advantages of high energy utilization and no exhaust emission. The motor is the core component of an electric tractor's drive system. Its characteristics and control directly affect a tractor's operating efficiency, operating quality, and energy consumption. A motor drive control scheme based on a characteristic curve at the maximum efficiency of an electric motor was adopted to address the problems of low motor power utilization and short continuous operation time on a full charge in electric tractors. By leveraging methods to obtain characteristic curves at the lowest fuel consumption for gasoline engines, we determined the characteristic curve at the maximum efficiency for a motor in a crawler-type electric tractor. Plowing is the most basic form of tractor operation, and it represents the agricultural work that accounts for most of a tractor's use. A field test was conducted on the drive control in plowing operation based on the curve, and the energy consumed to plow each $\mathrm{m}^{2}$, continuous plowing operation time on a full charge, and operating efficiency were tested. The test results showed plowing power consumption per $\mathrm{m}^{2}$ of about $8.40 \times 10^{-3} \mathrm{kWh}$ and work efficiency of $707.07 \mathrm{~m}^{2} / \mathrm{h}$. Compared with the traditional tractor, the cost of plowing $1 \mathrm{~m}^{2}$ by the crawler-type electric tractor was reduced by $20.3 \%-32.5 \%$. Because the control improves operating efficiency, battery energy consumption is reduced and continuous operation time is extended; hence, the control achieves its purpose.

\section{Introduction}

In recent years, with the increasing energy crisis and environmental pollution, green agriculture has been advocated all over the world, including environmental protection and the greening of agricultural power. As one of the main types of power machinery used in agriculture, tractors take on agricultural tasks such as farmland construction, plowing, cultivation, plant protection, and harvesting. Traditional tractors are mainly driven by gasoline or diesel engines, which have a wide range of optional horsepower, but they have the disadvantages of low energy conversion efficiency, high noise, and serious environmental pollution. Compared with the traditional internal combustion engine tractor, the electric tractor has the advantages of energy-saving, environmental protection, safety, and high efficiency [1] and is an effective way to solve the energy and environmental protection problems caused by agricultural machinery.

Since the late 1960s, many developed countries have studied pure electric tractors. For example, in 1969, the ElecTrak series of garden tractors were launched by General Electric in the United States [2], which was the beginning of the development of modern electric tractors. The Elec-Trak series went out of production in the mid-1970s. Pure electric tractors during this period had a low power range and were microelectric tractors, which were mainly used for operations such as gardening and snow shoveling, but were not suitable for field operation. Since the 1990s, with the rapid development of power electronic and battery technologies, electric tractors have been developed for their ease of operation, high reliability, networking, and automation [2-8]. Tractor and farm machinery manufacturers such as John 
Deere, Fendt, Solectrac, Rigitrac, Claas, Escorts, Kubota, and Schaffer have been working on electrification of farm machinery and have showcased their electric tractor prototypes at trade exhibitions, and pilot scale implementations are in process [1]. In 2017, Fendt launched the Vario, a practical, allelectric compact tractor with $50 \mathrm{~kW}$ power output, which can operate for up to five hours under actual operating conditions. The energy source is a $650 \mathrm{~V}$ high-capacity lithium-ion battery with a capacity of around $100 \mathrm{kWh}$. The tractor was first used in 2018 in limited numbers [7]. In June 2020, the $5 \mathrm{~g}+$ hydrogen fuel driverless electric tractor jointly built by Qinghua University Tianjin High End Equipment Research Institute and Henan Luoyang Advanced Manufacturing Industry R \& D Base was officially released in Luoyang, China [8]. The tractor adopts a mushroom head GPS (global positioning system) antenna, millimeter wave radar, big data cloud platform, and other technologies [8].

It can be seen that many countries have made some achievements in the development and application of electric tractor prototypes. Scholars around the world have made contributions to the theoretical research of electric tractors [9]. Matache et al. [10] carried out plowing experiments on a small-power electric tractor at different depths and speeds and assessed its autonomy and efficiency with a single battery charge. The results were used to establish the optimal working regime of the electric tractor during plowing work. Yoo et al. [11] used the Simulink-based ASM (automotive simulation model) and the CarSim, which simulate and interpret the dynamic characteristics of tractors, and analyzed the design factors of an electric tractor. Their study could serve as the basis for research on the comprehensive dynamic interpretation necessary to design an electric tractor and could provide guidelines for designing an electric motor-based system. Chen et al. [12] proposed a method of powertrain parameter matching and optimization design for electric tractors based on a dual-motor coupling drive mode. Future research on electric tractors will focus on the development of new motors, effective motor control technology, efficient and energy-saving low-cost batteries and battery-control strategies, continuously variable transmissions, and unmanned driving technology. Electric tractors will be more reliable, more intelligent, safer, more efficient, cleaner, and more energy-saving.

As with all-electric vehicles, the motor is the core component of an electric tractor drive system. Its characteristics and control directly affect a tractor's operating efficiency, operating quality, and energy consumption. When an electric tractor works in the field, the working speed is not high, but the required torque is large. Due to the diversity of operation, complexity of soil characteristics, and other factors, the load characteristics have great randomness and unpredictability. Therefore, the operating conditions of electric tractors and electric vehicles are quite different and so are the requirements of motor output characteristics. Electric tractors have had the problems of low motor power utilization and short operation time on a full charge. A literature survey reveals few studies on the key technology applied to motor characteristics and control schemes. Liu et al. studied how to improve the electrical conversion efficiency of an electric tractor motor and designed a load torque-based control strategy using particle swarm optimization, which provides a novel method of fabricating a more efficient electric motor used in the traction of an off-road vehicle [13]. According to the fuzzy self-tuning PID (proportion integration differentiation) control strategy in the normal working mode and limp control strategy in the failure mode, Shang et al. verified the effectiveness of the control strategy by simulation [14]. However, there is no relevant literature on the optimal working curve control of an electric tractor, while this kind of research has been seen in hybrid electric vehicles. Wang et al. [15] developed a motor optimal working curve control strategy for hybrid electric vehicles, and through a simulation comparison with the logic threshold control strategy, it was shown that the motor optimal working curve control strategy can reduce the vehicle fuel consumption by $9.5 \%$ per $100 \mathrm{~km}$ and increase the average working efficiency of the motor by $23 \%$. We studied an electric motor mounted on a crawler-type tractor and determined its maximum efficiency characteristic curve. We implemented the motor control based on the curve for the tractor drive control. The goal is for the motor to operate in the high efficiency zone in the field to reduce energy consumption and extend its continuous operation time on a full charge.

\section{Tractor Systems and Parameters}

We carried out the overall design, selection of main parts, power transmission system design and parameter matching, component processing, system assembly, and trial-production of a prototype crawler-type electric tractor consisting of four main systems. The power supply system includes a power battery unit, power management system, and auxiliary power supply. The electric drive system includes a drive motor, motor control unit, transmission system, driving wheels, and tracks. The vehicle control system includes a vehicle control unit and network communication system. The auxiliary system includes an onboard display and other systems. A photo of the crawlertype electric tractor is shown as Figure 1.

We designed the power transmission system of the tractor. Because the tractor includes an electric lifting device, electric energy from the battery is required by both the drive motor and lifting motor. The electrical energy from the battery is converted to mechanical energy through the drive motor and the lifting motor. The power of the drive motor is transferred to the gearbox and then to the drive shaft to propel the tractor and the power takeoff shaft for rotary tillage. The power of the lifting motor is transferred to the lifter to lift agricultural machinery. The power transmission route is shown in Figure 2. The aerial view of the power transmission system is shown in Figure 3. The tractor's powertrain specifications are listed in Table 1.

\section{Methods}

3.1. Test of Motor Output Characteristics. The input and output characteristics of the electric tractor's motor, including motor torque-rotational speed and motor system 


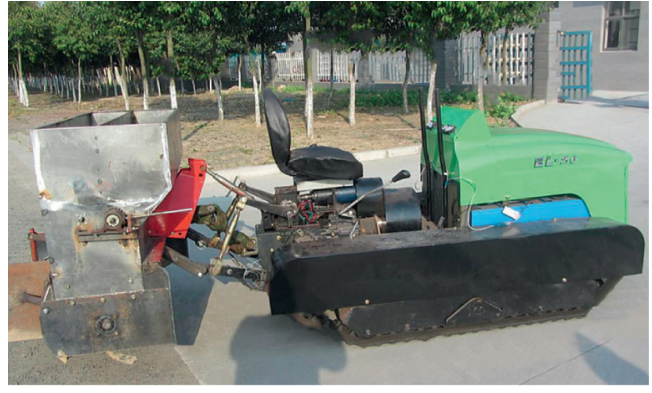

Figure 1: Photo of crawler-type electric tractor.

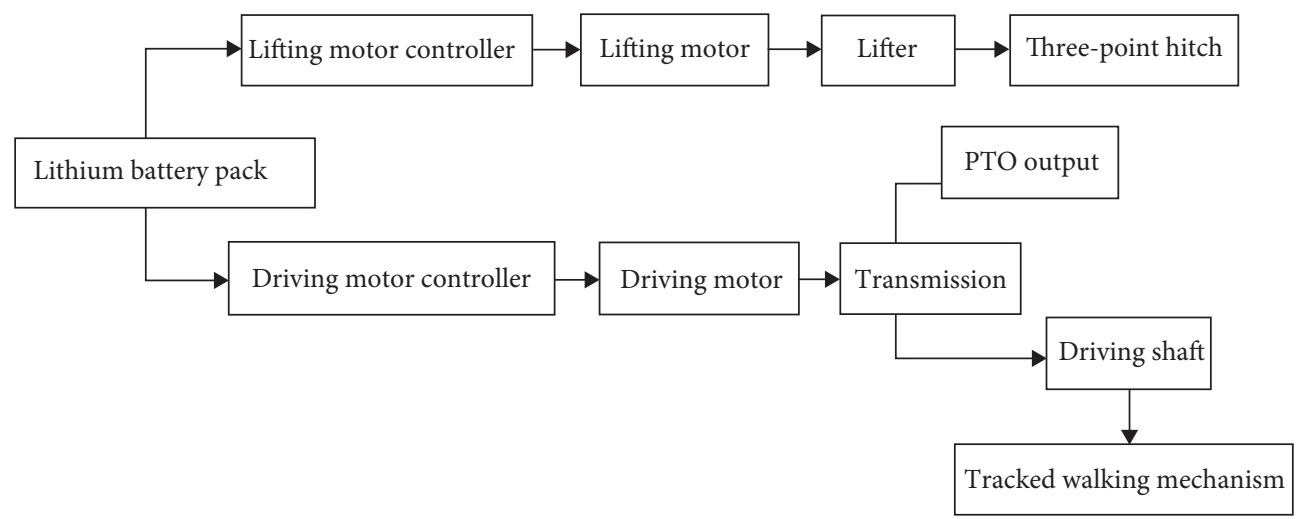

Figure 2: Power transmission route.

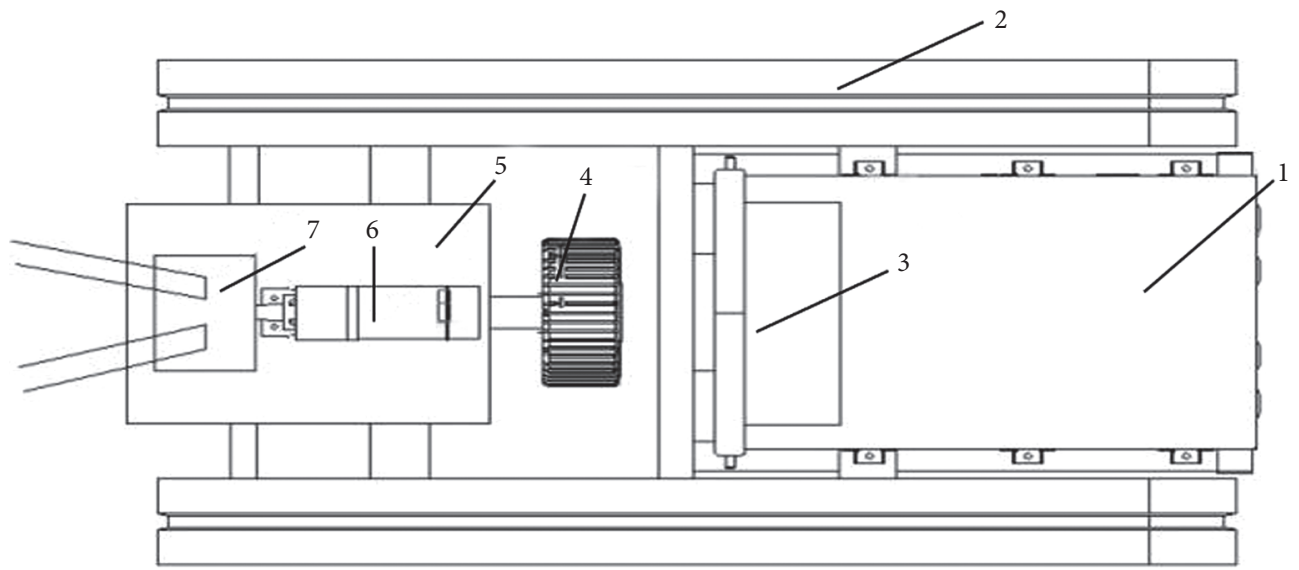

Figure 3: Aerial view of power transmission system: (1) power battery; (2) track; (3) driving motor controller; (4) driving motor; (5) gearbox; (6) lifting motor; (7) lift device.

efficiency, were tested on a power takeoff shaft test bench. A photo of the motor output characteristic test site is shown as Figure 4. The method of obtaining the test data was to connect the CAN bus communication interface card to the CAN bus network of the whole machine to collect the data on the CAN bus. Then, according to the CAN protocol manual provided by the manufacturers of the battery and motor, the date obtained was analyzed and saved using the CAN debugging software package CANalyst, such as output torque and rotational speed of the motor, voltage and current of the motor controller DC (direct-current) bus, state of charge (SOC) and capacity of the battery, and temperatures of the motor controller and motor. The CAN bus communication interface card was the type of USBCANI manufactured by Beijing Itekon. An image of the USBCAN-I CAN bus communication interface card is shown in Figure 5.

During the motor torque-rotational speed characteristic test, we set the voltage of the DC bus of the motor controller to the rated voltage of $96 \mathrm{~V}$. In the high-rotational speed power takeoff gear, while maintaining the position of the accelerator, we measured the motor output torque and rotational speed using a dynamometer to apply different torques to the power takeoff shaft. Motor torque-rotational 
TABle 1: Powertrain specification parameters.

\begin{tabular}{|c|c|c|}
\hline Item & Parameter & Value \\
\hline \multirow{4}{*}{ Overall vehicle parameters } & Overall weight $(\mathrm{kg})$ & 1100 \\
\hline & Track ground length (m) & 1.675 \\
\hline & Track path $(\mathrm{m})$ & 1.175 \\
\hline & Equivalent wheel radius $(\mathrm{m})$ & 0.2 \\
\hline \multirow{6}{*}{ Battery system } & Battery type (model) & Lithium iron phosphate battery (CA180FI) \\
\hline & Nominal cell voltage $(\mathrm{V})$ & 3.2 \\
\hline & Nominal cell capacity (Ah) & 180 (0.3 C, discharging) \\
\hline & Battery pack configuration & One in parallel and 30 in series \\
\hline & Rated output voltage of battery pack $(\mathrm{V})$ & 96 \\
\hline & Operating voltage range of battery pack $(\mathrm{V})$ & $84-109.5$ \\
\hline \multirow{5}{*}{ Motor drive system } & Motor type (model) & Disc brushless DC motor (PWZD7.5A3) \\
\hline & Rated (maximum) power $(\mathrm{kW})$ & $7.5(15)$ \\
\hline & Rated voltage $(\mathrm{V})$ & 96 \\
\hline & Rated (maximum) torque $(\mathrm{Nm})$ & $29.8(65)$ \\
\hline & Motor controller & Hefei New Generation EVC401-085P \\
\hline Gearbox & Overall transmission ratio on I/II/III gear & $76.576 / 42.366 / 23.398$ \\
\hline Power output & Power takeoff on low/high gear & $4.458 / 2.273$ \\
\hline
\end{tabular}

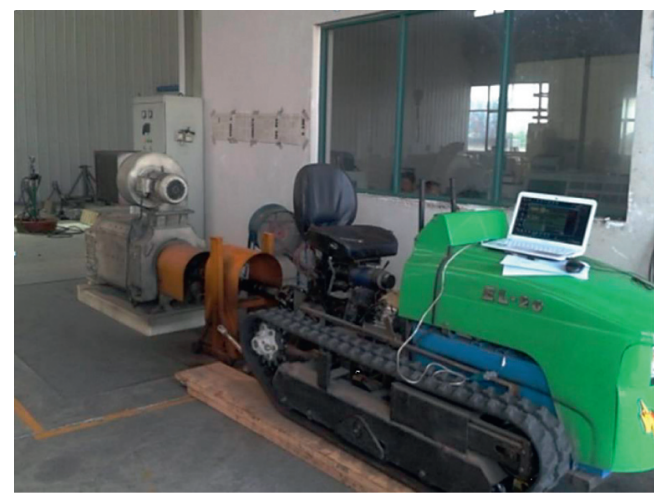

FIgURE 4: Motor output test.

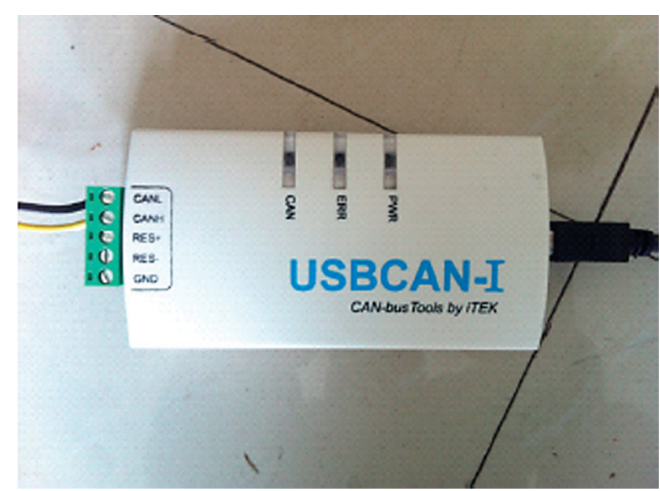

FIgURE 5: USBCAN-I CAN bus communication interface card.

speed characteristic tests were carried out with the accelerator pedal at positions of $28.5 \%, 42.6 \%, 48.7 \%, 71.2 \%$, and $100 \%$. The test results are shown in Figure 6.

The efficiency of the motor system is determined according to the ratio of the system input power and motor output power. The input power is the electric power input by the DC bus of the motor controller, and the output power is the mechanical power at the motor shaft end,

$$
\eta_{e}=\frac{n_{e} T_{e}}{9.55 U I} \times 100 \%
$$

where $\eta_{e}$ is the efficiency of the motor system (\%), $n_{e}$ is the motor rotational speed $(\mathrm{r} / \mathrm{min}), T_{e}$ is the motor torque $(\mathrm{Nm})$, and $\mathrm{U}$ and $\mathrm{I}$ are the voltage $(V)$ and current $(\mathrm{A})$, respectively, of the motor controller DC bus.

We set the motor controller DC bus to the rated voltage of $96 \mathrm{~V}$. In the high-rotational speed power takeoff gear, while maintaining the accelerator pedal position, we measured the motor output torque and rotational speed and the voltage and current of the DC bus using a dynamometer to apply different torques to the power takeoff shaft. We calculated the efficiency of the motor system using equation (1). The results are shown in Table 2. Figure 7 shows a diagram of the efficiency of the motor system with the motor torque and rotational speed, obtained by two-dimensional interpolation on the data listed in Table 2.

\subsection{Determination of Motor Characteristic Curve at Maxi-} mum Efficiency. For gasoline vehicles, the most cost-effective operating conditions at certain power supplied by engines are obtained according to the characteristic curves at lowest fuel consumption, which can be obtained as follows [16]: (1) find the lowest fuel consumption curve at a certain engine output power from the envelope of the engine power-fuel consumption rate load characteristic curves; (2) use the curve to find the most cost-effective operating condition (rotational speed and load) at a certain engine output power; and (3) label the rotational speed and load rate of the most cost-effective operation under each power level on the external characteristic curve.

We followed the above method to determine the highest efficiency characteristic curve for our crawler-type electric tractor motor, from which the most efficient operating point (rotational speed and torque) for motor output power can be found. The process is as follows. 


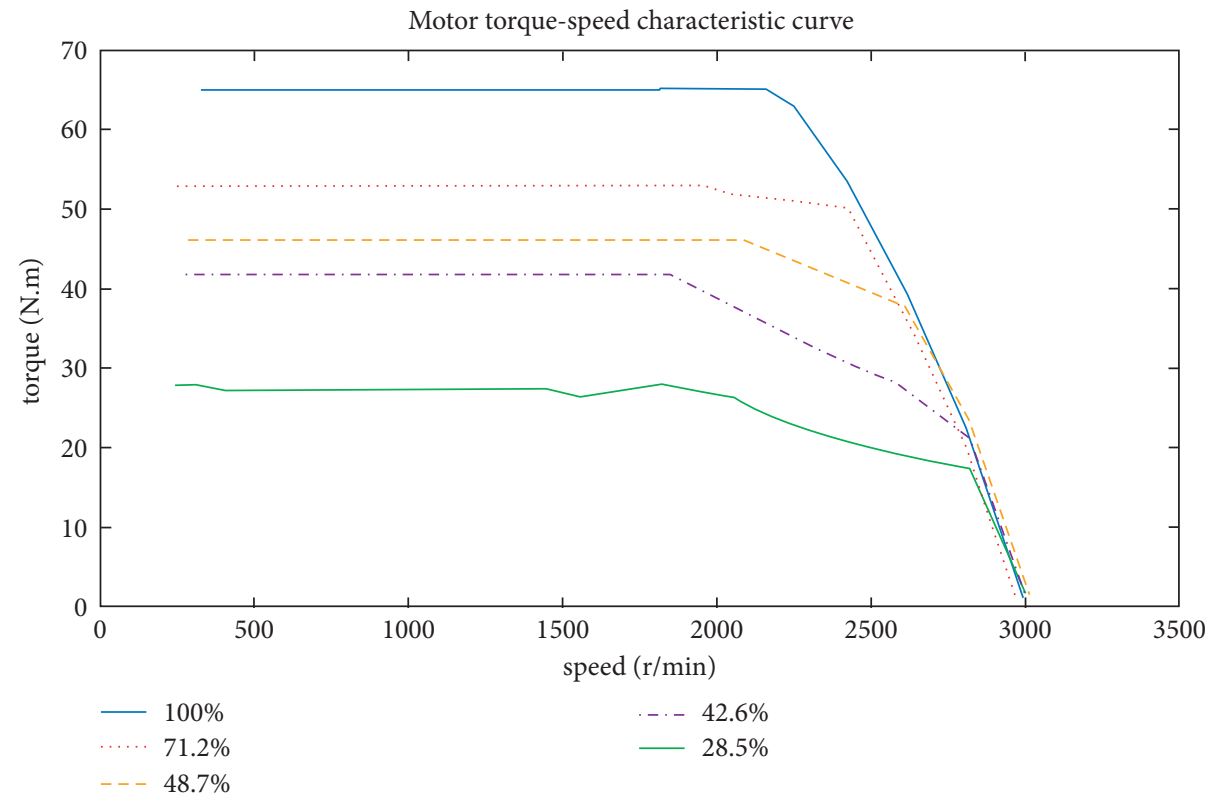

FIgURE 6: Motor torque-rotational speed characteristic curves.

Table 2: Motor system efficiency test data.

\begin{tabular}{lcccccccccc}
\hline \multirow{2}{*}{ Motor efficiency } & \multicolumn{9}{c}{ Rotational speed $(\mathrm{r} / \mathrm{min})$} \\
& & 0 & 400 & 800 & 1200 & 1600 & 2000 & 2400 & 2800 & 3000 \\
\hline Torque $(\mathrm{Nm})$ & 51.23 & 0.7 & 0.78 & 0.85 & 0.86 & 0.81 & 0.82 & 0.79 & 0.78 & 0.78 \\
& 45.64 & 0.7 & 0.78 & 0.86 & 0.87 & 0.82 & 0.82 & 0.79 & 0.78 & 0.78 \\
& 40.52 & 0.7 & 0.79 & 0.86 & 0.88 & 0.85 & 0.82 & 0.79 & 0.78 & 0.78 \\
& 35.36 & 0.7 & 0.80 & 0.86 & 0.89 & 0.87 & 0.82 & 0.78 & 0.78 & 0.78 \\
& 30.86 & 0.7 & 0.81 & 0.87 & 0.9 & 0.88 & 0.85 & 0.79 & 0.78 & 0.78 \\
& 25.72 & 0.7 & 0.82 & 0.88 & 0.9 & 0.9 & 0.87 & 0.82 & 0.78 & 0.78 \\
& 20.64 & 0.7 & 0.82 & 0.87 & 0.9 & 0.91 & 0.9 & 0.86 & 0.8 & 0.78 \\
& 15.23 & 0.7 & 0.82 & 0.86 & 0.9 & 0.91 & 0.91 & 0.9 & 0.88 & 0.8 \\
& 10.38 & 0.7 & 0.81 & 0.85 & 0.89 & 0.91 & 0.91 & 0.91 & 0.91 & 0.9 \\
& 5.14 & 0.7 & 0.77 & 0.82 & 0.87 & 0.88 & 0.89 & 0.9 & 0.91 & 0.9 \\
& 0 & 0.7 & 0.7 & 0.7 & 0.7 & 0.7 & 0.7 & 0.7 & 0.7 & 0.7 \\
\hline
\end{tabular}

(1) In the motor rotational speed range of 0 to $3000 \mathrm{r} / \mathrm{min}$, the data points from every revolution were used to construct a 3001-dimensional row vector for the rotational speed, $n=(0,1,2, \ldots, 3000)$. In the power range of 0 to $15 \mathrm{~kW}$, the data points for every $0.1 \mathrm{~kW}$, starting at $1 \mathrm{~kW}$, were used to construct a 141-dimensional row vector for power, $p=(1,1.1,1.2, \ldots, 15)$.
(2) The vector $n$ was replicated in 141 rows to form a $141 \times 3001$ matrix of rotational speed, denoted by $\mathrm{N}$, and $p$ was replicated in 3001 columns to form a $141 \times 3001$ matrix of power, denoted by P. A $141 \times 3001$ matrix of torque $T_{t q}$ can be determined according to the rotational speed matrix $N$ and the power matrix $P$. Each element of the torque matrix $T_{t q}$ was calculated as

$$
T_{t q}(i, j)=\frac{9550 P(i, j)}{N(i, j)} \quad(i=1,2, \ldots \ldots, 141 ; j=1,2, \ldots \ldots, 3001),
$$

where $T_{t q}(i, j)$ is the element in row $i$ and column $j$ of the torque matrix $T_{t q}, P(i, j)$ is the element in row $i$ and column $j$ of the power matrix $P$, and $N(i, j)$ is the element in row $i$ and column $j$ of the rotational speed matrix $N$.

(3) The $141 \times 3001$ motor system efficiency matrix $E$ was calculated from the test data of the motor system efficiency in Table 2 and the matrices $N$ and $T_{t q}$ with two-dimensional interpolation. Each row in $E$ represents the efficiency of the motor for different motor rotational speeds at the same power.

(4) Searching for the data and position corresponding to a maximum value in each row of the matrix $E$, one can obtain the highest efficiency and the 


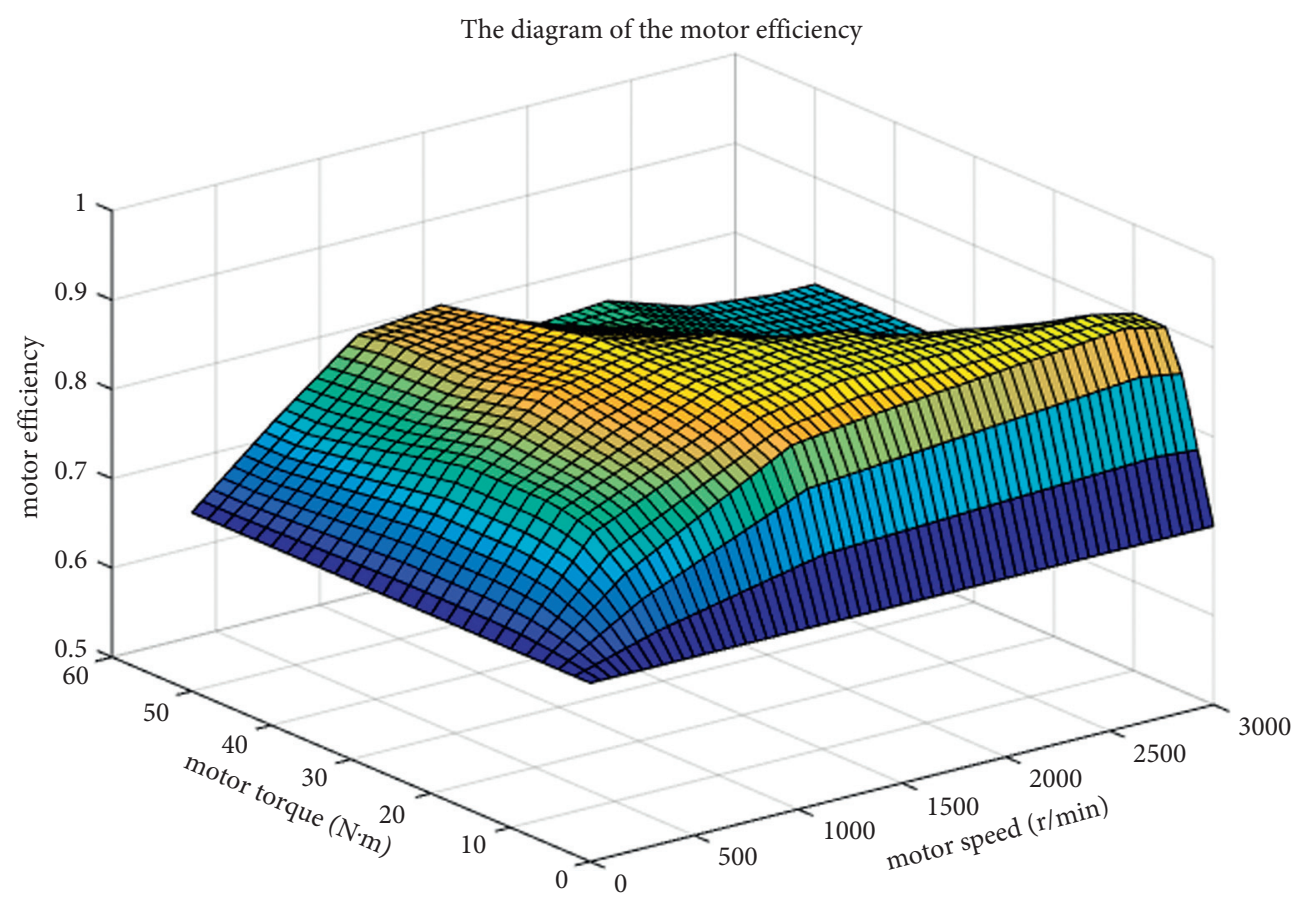

Figure 7: Motor efficiency diagram.

corresponding rotational speed at different amounts of power supplied by the motor. The most efficient operating point (rotational speed and torque) for a given power supplied by the motor can be obtained according to the motor rotational speed with the highest efficiency under a given power. The vector emax contains the maximum value extracted from each row of matrix $E$, the rotational speed values corresponding to each maximum value comprise the vector nmax, and the torque values calculated for each rotational speed value in nmax comprise the vector $t_{\max }$. The dimensions of emax, nmax, and tmax are all 141.

(5) The characteristic curve at the highest efficiency of the motor was plotted according to the motor power vector $p$ and rotational speed vector nmax, as shown in Figure 8. We also plotted the motor power-rotational speed external characteristic curve with the accelerator pedal at the $100 \%$ position, as shown in Figure 9.

3.3. Design and Development of Control System for CrawlerType Electric Tractor. We designed and developed the integrated control system of the crawler-type electric tractor. The crawler-type electric tractor control system, designed in this paper, consists mainly of a vehicle control unit, unit controllers, communication system, and operating system, as shown in Figure 10. The control system uses the vehicle unit as the core and controls the other units via CAN (controller area network) bus communication.

Based on the systematic analysis of the electric tractor control system, we designed the architecture of the vehicle control unit, as shown in Figure 11. It has two analog signal inputs, for the accelerator pedal and farm tool positioning. These two signals become standard $0-5 \mathrm{~V}$ signals after passing through their respective signal conditioning circuits, and these are input to the controller. The control unit has four input channels and four output channels for switching signals. It communicates with the PC (personal computer) through an RS232 (recommended standards 232) interface. A CAN bus channel is implemented for communication of the motor controller, energy management system, and instrument display.

The tractor performs tasks such as plowing, harrowing, rotary tilling, fertilizing, and sowing in the field and greenhouse. The vehicle control unit should combine different operating characteristics and adopt different control strategies to achieve predetermined control objectives. The flow of the control system is shown in Figure 12.

\section{Results}

Plowing is the most basic form of tractor operation, with the heaviest load and highest energy consumption. Therefore, we conducted field tests with a drive control strategy based on the maximum efficiency curve of the motor under the typical operating conditions of plowing. We tested the energy consumed to plow each $\mathrm{m}^{2}$, continuous plowing operation time on a full charge, and operating efficiency. The test results can be used to evaluate the cost-effectiveness and operating efficiency of our tractor. The test site is shown in Figure 13.

The electric tractor was driven to the test site. To ensure consistency of all tests, at the beginning of each test, the tractor power battery SOC was made to drop to $20 \%$, and then charging started and continued until the power battery SOC indicator read $100 \%$. The electrical energy consumed to charge the power battery from $20 \%$ to $100 \%$ (denoted by $Q$ 


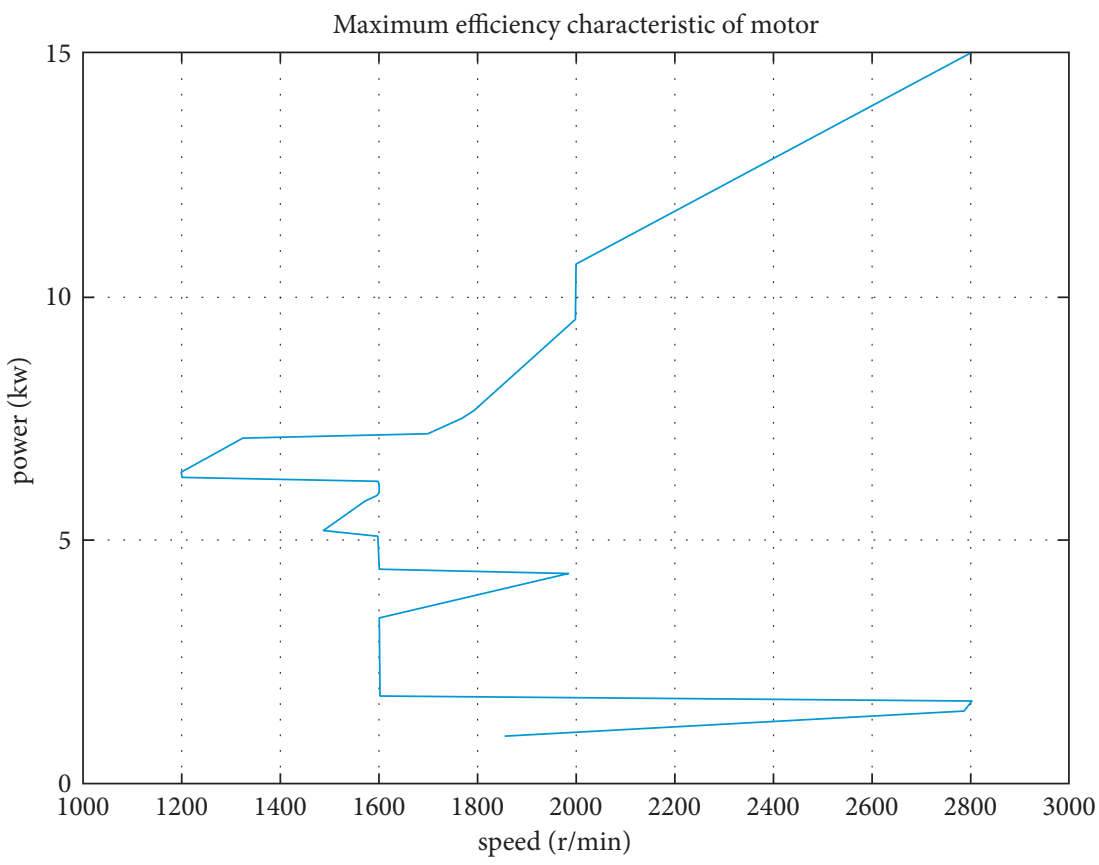

Figure 8: Motor maximum efficiency characteristic curve.

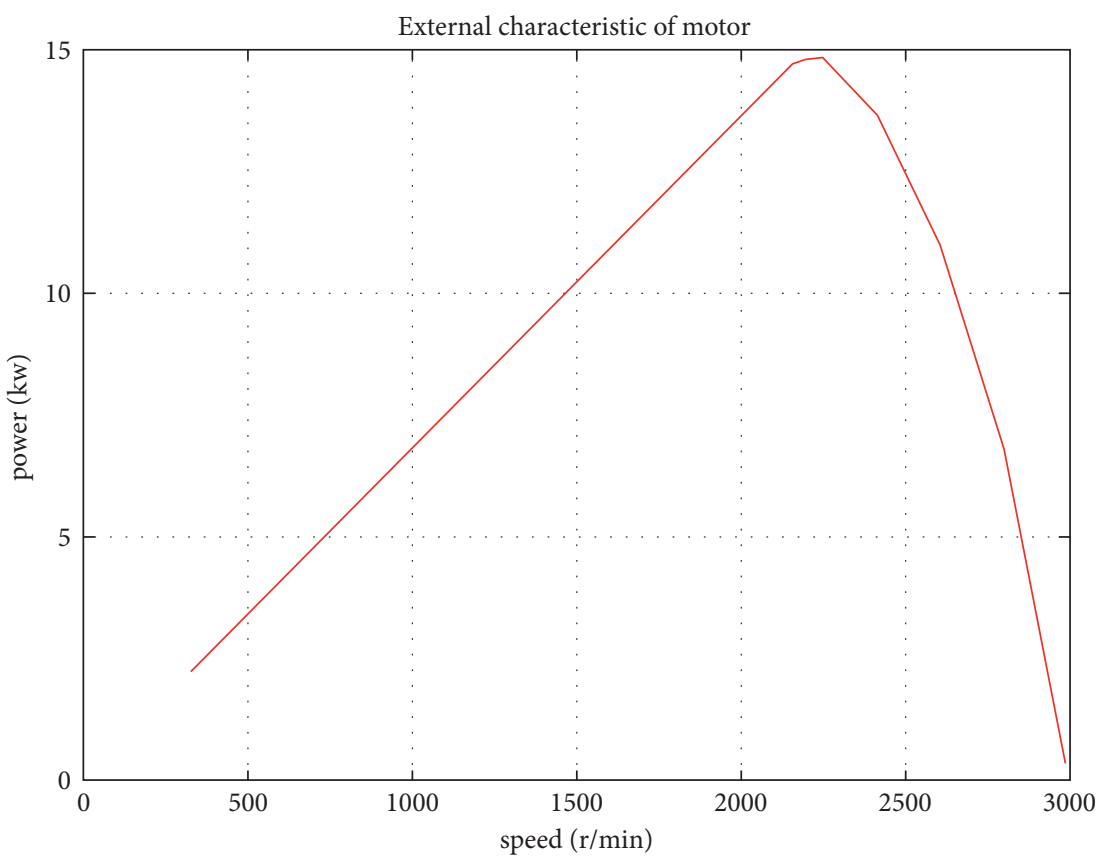

FiguRE 9: Motor external characteristic curve.

and measured in $\mathrm{kWh}$ ) was calculated using the charging voltage and current measured in real time. The CAN-bus communication interface card was connected to the CAN buses of the energy management system and charger. The measured charging voltage and current data of the charger were obtained from the data packets on the CAN bus.

After the tractor was fully charged, the plowing speed was set at $2 \mathrm{~km} / \mathrm{h}$ at first, and it plowed until the SOC dropped to $20 \%$. The continuous plow operation time $T$ (hours) was recorded. After the operation stopped, the plowing area $A\left(\mathrm{~m}^{2}\right)$ was measured. The test was run three times, with results as listed in Table 3 .

The electricity consumed to plow a $\mathrm{m}^{2}$ is

$$
q=\frac{Q}{A}
$$

where $q$ is the electricity consumed to plow each $\mathrm{m}^{2}(\mathrm{kWh} /$ $\left.\mathrm{m}^{2}\right), Q$ is the electrical energy consumed to charge the power battery from $20 \%$ to $100 \%(\mathrm{kWh})$, and $A$ is the plowing area $\left(\mathrm{m}^{2}\right)$. 


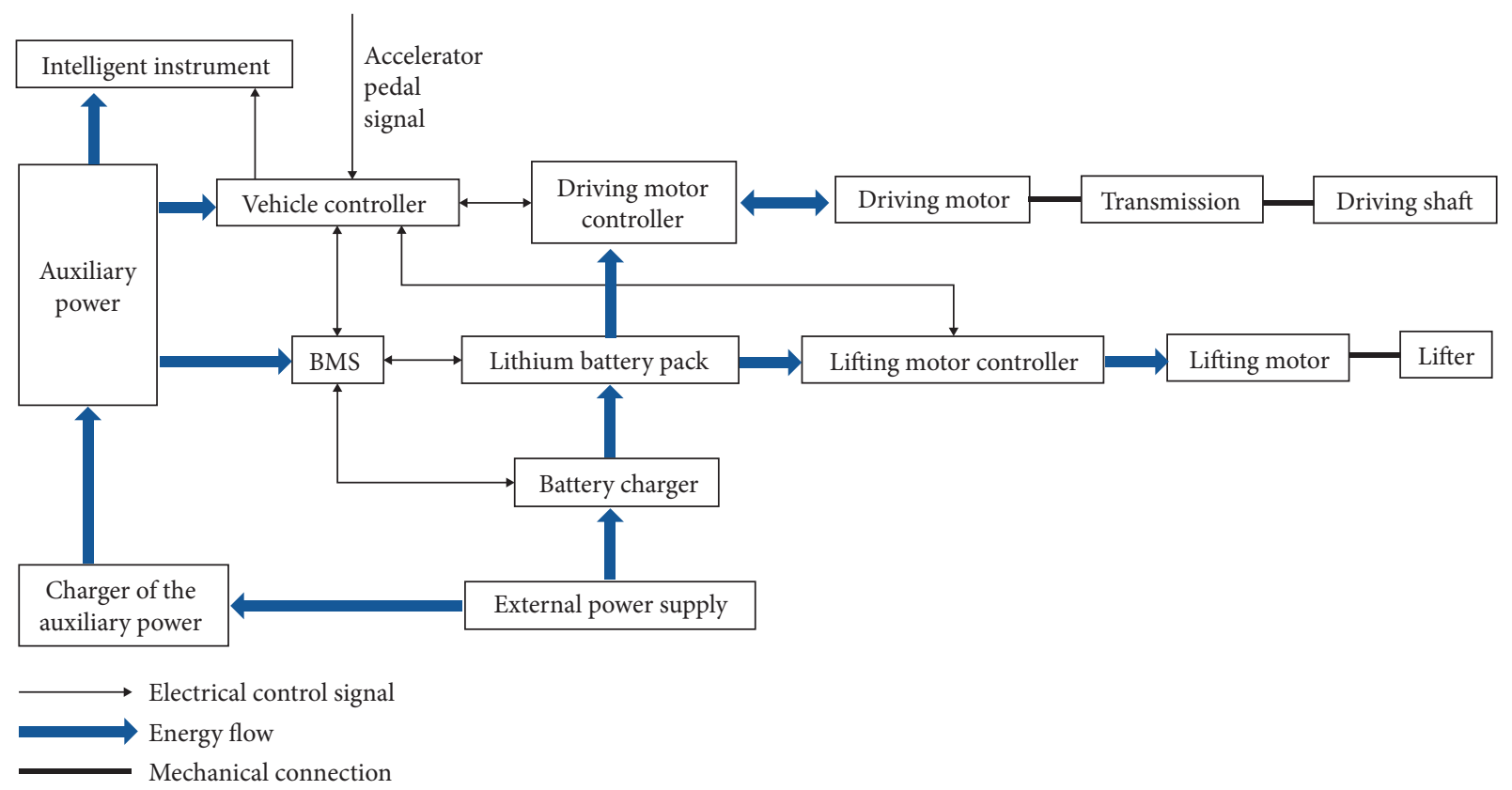

FIGURE 10: Block diagram of control system architecture.

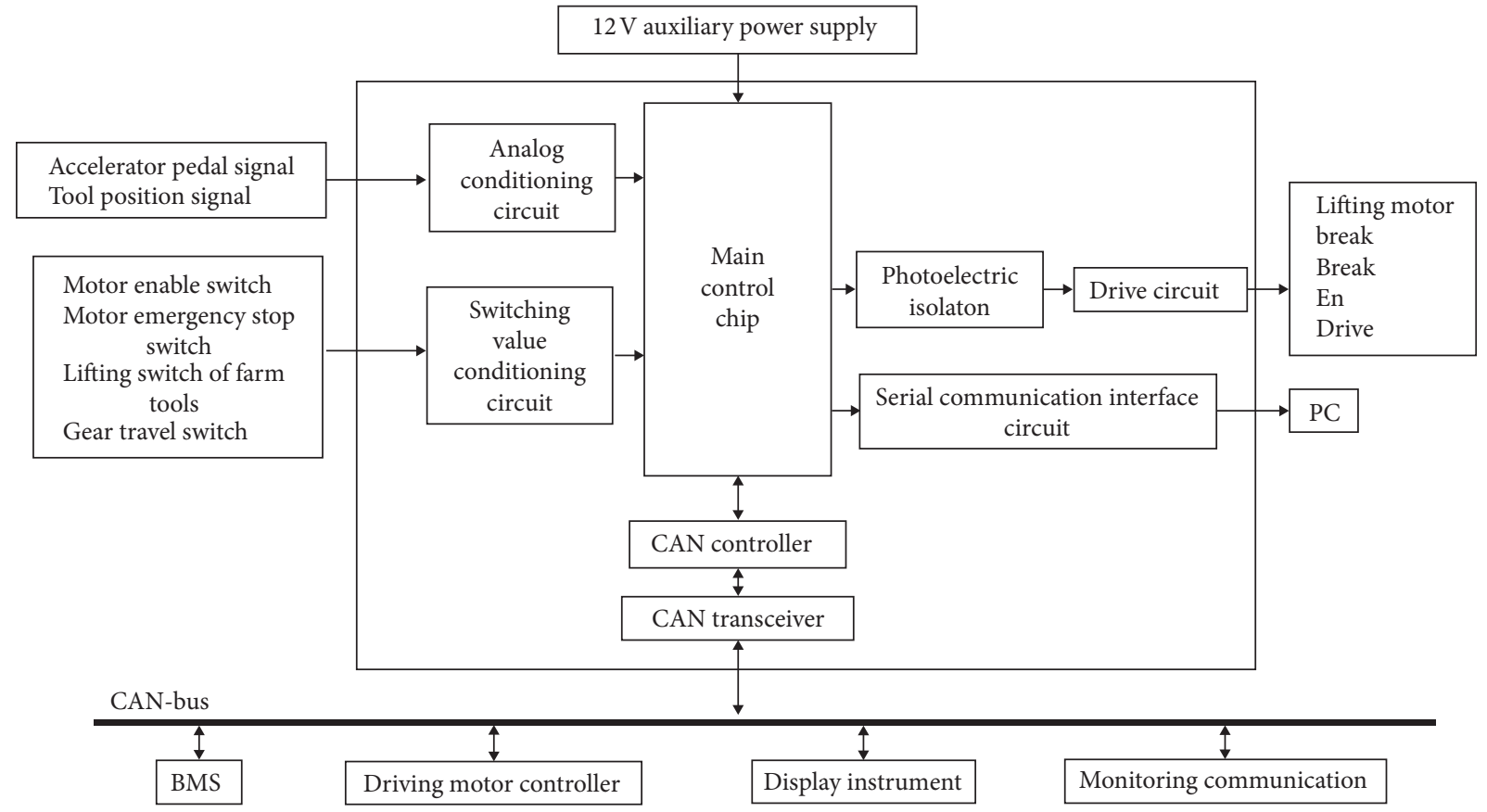

FIGURE 11: Block diagram of vehicle control unit architecture.

The plowing work efficiency is

$$
\eta=\frac{A}{T}
$$

where $\eta$ is the plowing work efficiency $\left(\mathrm{m}^{2} / \mathrm{h}\right)$ and $T$ is the plowing operation time $(h)$.

The plowing cost of $\mathrm{a} \mathrm{m}^{2}$ is

$$
Y=y \cdot q \text {, }
$$

where $Y$ is the plowing cost of $\mathrm{a} \mathrm{m}^{2}$ (yuan $/ \mathrm{m}^{2}$ ) and $y$ is the electricity rate (yuan/kWh).
Using the average over three results as the value of each parameter in equations (3)-(5), we can obtain that the plowing energy consumption per $\mathrm{m}^{2}$ was about $8.40 \times 10^{-3} \mathrm{kWh}$, the plowing efficiency was $707.07 \mathrm{~m}^{2} / \mathrm{h}$, and the cost of plowing $1 \mathrm{~m}^{2}$ was about $6.72 \times 10^{-3}$ yuan at an electricity rate of 0.8 yuan/kWh. Under the same operating conditions, a conventional diesel tractor consumes about $1.27-1.50 \times 10^{-3} \mathrm{~kg}$ diesel oil to plow $1 \mathrm{~m}^{2}$, and the cost of plowing $1 \mathrm{~m}^{2}$ is about $8.43-9.95 \times 10^{-3}$ yuan at 5.64 yuan per liter. Compared with the traditional tractor, the cost of plowing $1 \mathrm{~m}^{2}$ by 


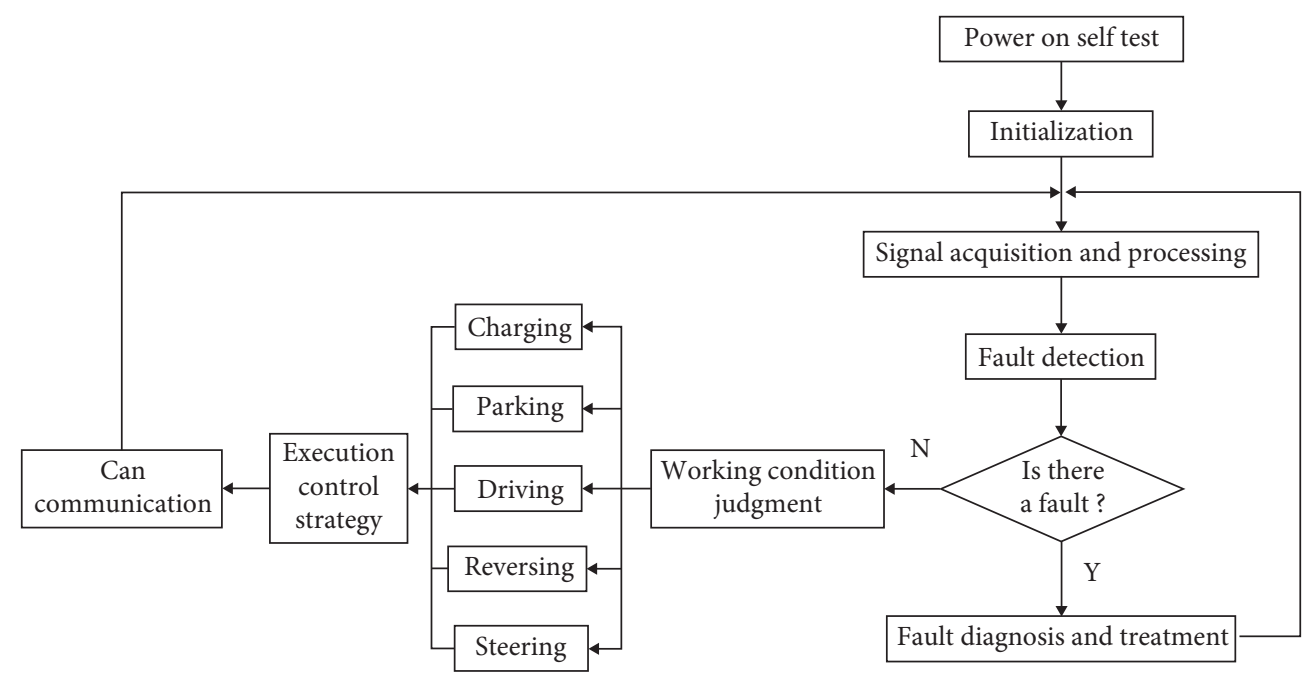

FIgUre 12: Control flowchart.

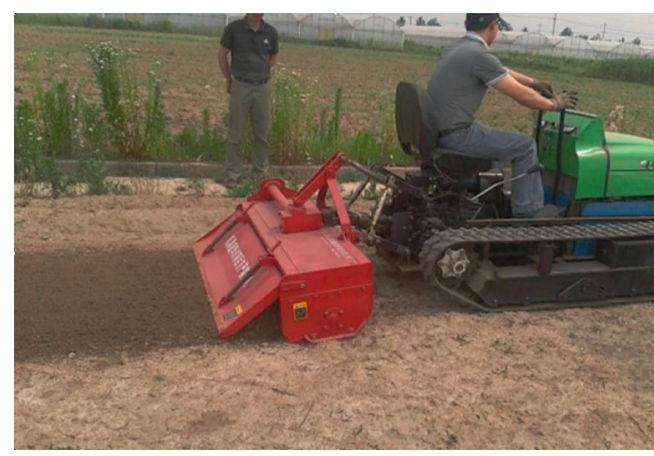

FIgURe 13: Field test.

TABLE 3: Test results.

\begin{tabular}{lccc}
\hline Trial & $\mathrm{Q}(\mathrm{kWh})$ & $\mathrm{T}(\mathrm{h})$ & $\mathrm{A}\left(\mathrm{m}^{2}\right)$ \\
\hline 1st test & 21.34 & 3.53 & 2500.01 \\
2nd test & 22.68 & 3.65 & 2580.01 \\
3rd test & 20.66 & 3.72 & 2620.01 \\
Mean & 21.56 & 3.63 & 2566.68 \\
\hline
\end{tabular}

our crawler-type electric tractor was reduced by $20.3 \%-$ $32.5 \%$. The results show that our electric tractor has good cost-effectiveness.

\section{Summary and Conclusions}

In tackling the practical problem of low motor efficiency of crawler-type electric tractors in field operation, we leveraged methods to obtain characteristic curves at the lowest fuel consumption for gasoline engines, defined the characteristic curve at the maximum efficiency of the motor on an electric tractor, and provided a method to determine the curve. We designed and developed the integrated control system of the crawler-type electric tractor. Then we applied a plowing operation drive control based on the obtained characteristic curve at the maximum efficiency of the motor and conducted tests of economy and efficiency of field plowing operation. The test results show that the plowing power consumption per $\mathrm{m}^{2}$ is about $8.40 \times 10^{-3} \mathrm{kWh}$, the cost of plowing a $\mathrm{m}^{2}$ is about $6.72 \times 10^{-3}$ yuan at an electricity rate of 0.8 yuan $/ \mathrm{kWh}$, and the plowing efficiency is $707.07 \mathrm{~m}^{2} / \mathrm{h}$. Compared with the traditional tractor, the cost of plowing $1 \mathrm{~m}^{2}$ by our crawler-type electric tractor was reduced by $20.3 \%-32.5 \%$. The test results indicate that the maximum motor efficiency control strategy allows the motor to operate at high efficiency, reducing the battery power consumption, extending the continuous operation time on a full charge, and achieving the control objective of improving operating performance and economy.
Abbreviations
ASM: Automotive simulation model
CAN: Controller area network
DC: Direct-current
GPS: Global positioning system
PC: Personal computer
PID: Proportion integration differentiation
RS232: Recommended standards 232
SOC: State of charge.

\section{Data Availability}

No data were used to support this study.

\section{Additional Points}

Motor torque-rotational speed and motor system efficiency tests were performed to obtain the input and output characteristics of our crawler-type electric tractor's motor. The highest efficiency characteristic curve for our crawler-type electric tractor motor by leveraging methods was determined to obtain characteristic curves at the lowest fuel consumption for gasoline engines. Conducted the energy consumed to plow each $\mathrm{m}^{2}$, continuous plowing operation time on a full charge, and operating efficiency tests on the characteristic curve at the maximum efficiency of the electric motor to verify good cost-effectiveness of our electric tractor. 


\section{Conflicts of Interest}

The authors declare that they have no conflicts of interest.

\section{Acknowledgments}

This research was supported by the Key Research and Development Project in Jiangsu Province (BE2018343-1) and Cyan Engineering Project in Jiangsu Universities (2020-06). We would like to express our gratitude to all those who have helped us during the writing of this thesis.

\section{References}

[1] A. Malik and S. Kohli, "Electric tractors: survey of challenges and opportunities in India," Materials Today: Proceedings, vol. 28, pp. 2318-2324, 2020.

[2] W. Arjharn, M. Koike, T. Takigawa, A. Yoda, H. Hasegawa, and B. Bahalayodhin, "Preliminary study on the applicability of an electric tractor (Part 1)," Journal Japanese Society Agricultural Machinery, vol. 63, no. 3, pp. 130-137, 2001.

[3] S. M. M. Ismail, G. Singh, and D. Gee-Clough, "A preliminary investigation of a combined slip and draught control for tractors," Journal of Agricultural Engineering Research, vol. 26, no. 4, pp. 293-306, 1981.

[4] L. Bodria and M. Fiala, "Design and testing of an electricpowered walking tractor," Journal of Agricultural Engineering Research, vol. 60, no. 1, pp. 57-62, 1995.

[5] W. Arjharn, M. Koike, T. Takigawa, A. Yoda, H. Hasegawa, and B. Bahalayodhin, "Preliminary study on the applicability of an electric tractor (Part 2)," Journal of the Japanese Society of Agricultural Machinery, vol. 63, no. 5, pp. 92-99, 2001b.

[6] Y. Ueka, J. Yamashita, K. Sato, and Y. Doi, "Study on the development of the electric tractor," Engineering in Agriculture, Environment and Food, vol. 6, no. 4, pp. 160-164, 2013.

[7] Fendt e100, "Vario: The Battery-Powered Compact Tractor," 2017, https://www.fendt.com/int/fendt-e100-vario.html.

[8] J. H. Tao, "First tractor of China released the first 5G + hydrogen fuel electric tractor in China," Contemporary Agricultural Mach, vol. 7, p. 29, 2020, in Chinese.

[9] R. O. Magalhães, M. V. D. Assunção, J. P. M. Santos et al., "Review on applications of electric vehicles in the countryside," Ciência Rural, vol. 47, no. 7, Article ID e20161076, 2017.

[10] M. G. Matache, M. Cristea, I. Găgeanu et al., "Small power electric tractor performance during ploughing works," INMATEH Agricultural Engineering, vol. 60, no. 1, pp. 123$129,2020$.

[11] I. Yoo, T. Lee, B. Kim, J. Hur, K. Yeon, and G. Kim, "Performance interpretation method for electrical tractor based on model-based design," in Proceedings of the 2013 International Conference on IT Convergence and Security (ICITCS), pp. 1-4, Macao, China, December 2013.

[12] Y. Chen, B. Xie, B. Xie, and Y. Du, "Powertrain parameter matching and optimal design of dual-motor driven electric tractor," International Journal of Agricultural and Biological Engineering, vol. 12, no. 1, pp. 33-41, 2019.

[13] M. Liu, L. Xu, and Z. Zhou, "Design of a load torque based control strategy for improving electric tractor motor energy conversion efficiency," Mathematical Problems in Engineering, vol. 2016, Article ID 2548967, 14 pages, 2016.

[14] G. G. Shang, J. Z. Zhang, and J. J. Zhang, "Research on control strategy of tracked electric tractor drive system," Journal of Chongqing University of Technology (Natural Science), vol. 31, no. 11, pp. 32-38, 2017.
[15] Q. N. Wang, S. T. Sun, E. C. Ji, and C. H. Liu, "Motor optimal operation line's establishment and application of HEV," Transactions of the Chinese Society for Agricultural Machinery, vol. 39, no. 1, pp. 11-14, 2008.

[16] Z. S. Yu, Automobile Theory, China Machine Press, Beijing, China, 5th edition, 2009. 